\title{
Expression of SDF- $\mid \alpha$ and nuclear CXCR4 predicts lymph node metastasis in colorectal cancer
}

\author{
N Yoshitake ${ }^{1,2}$, H Fukui ${ }^{*, 1}$, H Yamagishi' ${ }^{1,2}$, A Sekikawa', S Fujii', S Tomita', K Ichikawa', J Imura', H Hiraishi' \\ and T Fujimori'
}

'Department of Surgical and Molecular Pathology, Dokkyo University School of Medicine, 880, Kitakobayashi, Mibu, Shimotsuga, Tochigi, 32 I-0293,

Japan; '2Department of Gastroenterology, Dokkyo University School of Medicine, 880, Kitakobayashi, Mibu, Shimotsuga, Tochigi, 32 I-0293, Japan

\begin{abstract}
Although stromal cell-derived factor (SDF)- $\mid \alpha$ and its receptor CXCR4 are experimentally suggested to be involved in tumorigenicity, the clinicopathological significance of their expression in human disease is not fully understood. We examined SDF- $\mid \alpha$ and CXCR4 expression in colorectal cancers (CRCs) and their related lymph nodes (LNs), and investigated its relationship to clinicopathological features. Specimens of 60 primary CRCs and 27 related LNs were examined immunohistochemically for not only positivity but also immunostaining patterns for SDF- $\mid \alpha$ and CXCR4. The relationships between clinicopathological features and SDF- $\mid \alpha$ or CXCR4 expression were then analysed. Stromal cell-derived factor- $\mid \alpha$ and CXCR4 expression were significantly associated with LN metastasis, tumour stage, and survival of CRC patients. Twenty-nine of 47 CXCR4-positive CRCs (6I.7\%) showed clear CXCR4 immunoreactivity in the nucleus and a weak signal in the cytoplasm (nuclear type), whereas others showed no nuclear immunoreactivity but a diffuse signal in the cytoplasm and at the plasma membrane (cytomembrane type). Colorectal cancer patients with nuclear CXCR4 expression showed significantly more frequent LN metastasis than did those with cytomembrane expression. Colorectal cancer patients with nuclear CXCR4 expression in the primary lesion frequently had cytomembrane CXCR4-positive tumours in their LNs. In conclusion, expression of SDF- $\mid \alpha$ and nuclear CXCR4 predicts LN metastasis in CRCs.
\end{abstract}

British Journal of Cancer (2008) 98, 1682-1689. doi: 10. I038/sj.bjc.6604363 www.bjcancer.com

Published online 29 April 2008

(c) 2008 Cancer Research UK

Keywords: chemokines; SDF- I $\alpha$; CXCR4; colorectal cancer; lymph node metastasis

Chemokines belong to the small molecular chemoattractive cytokine family and are classified into four groups $\left(\mathrm{CXC}, \mathrm{CXC}_{3}\right.$, $\mathrm{CC}$, and $\mathrm{C}$ ) according to the positions of the four conserved cysteine residues (Baggiolini et al, 1997; Rollins, 1997). Their actions are mediated by G-protein-coupled receptors, which are characterised by a seven-transmembrane-spanning domain. Stromal cell-derived factor (SDF)- $1 \alpha$, which was originally cloned from murine bone marrow (Tashiro et al, 1993), is a member (CXC chemokine ligand 12) of the CXC subfamily and exerts an effect through its specific receptor CXCR4 (Tachibana et al, 1998; Zou et al, 1998). The SDF-1 $\alpha$-CXCR4 axis was initially found to be stimulated by the homing of lymphocytes to inflammatory tissues and has recently been found to be involved in many areas of immunology and human development, including organogenesis, vascularisation, haematopoiesis, and embryogenesis (Murdoch, 2000). Moreover, recent studies have reported that SDF- $1 \alpha$ and CXCR4 may play important roles in cell survival, proliferation, chemotaxis, migration, and adhesion (Vlahakis et al, 2002; Kayali et al, 2003; Soriano et al, 2003; Fernandis et al, 2004; Hartmann et al, 2005), suggesting that the SDF- $1 \alpha-$ CXCR4 axis is involved in tumorigenicity. However, although these biological functions of

*Correspondence: Dr H Fukui; E-mail: h-fukui@dokkyomed.ac.jp Received 12 December 2007; revised 27 March 2008; accepted 27 March 2008; published online 29 April 2008
SDF- $1 \alpha$ and CXCR4 were examined mainly in in vitro studies, the pathophysiological significance of SDF- $1 \alpha$ and CXCR4 in human disease still remains unclear. Therefore, we examined the expression of SDF- $1 \alpha$ and CXCR 4 in colorectal cancers (CRCs) and their related lymph nodes (LNs), and investigated the relationship between this expression and clinicopathological features. In addition, because our immunohistochemical analysis of CRC cells revealed nuclear expression of CXCR4, which is normally expressed in the cytomembrane, we also investigated the presence of CXCR4 protein in the nucleus and its pathophysiological significance.

\section{MATERIALS AND METHODS}

\section{Patients and tissue samples}

A total of 60 patients with CRC who underwent surgery or endoscopic resection at Dokkyo University School of Medicine between 1990 and 2003 were enrolled. Patients with familial adenomatous polyposis, hereditary nonpolyposis colorectal cancer, inflammatory bowel disease, or other malignancies were excluded, as were patients who had received preoperative treatment such as chemotherapy or radiation therapy. The study was performed with the approval of the Dokkyo University Surgical Pathology Committee, and informed consent was obtained from all patients. 
Table I Clinicopathological features of the patients with colorectal cancer

\begin{tabular}{lc}
\hline Gender & \\
Man & $41(68.3 \%)$ \\
Woman & $19(31.7 \%)$ \\
Age (years, mean \pm s.d.) & $63.8 \pm 10.9(39-88)$ \\
Tumour location & \\
$\quad$ Colon & $49(81.7 \%)$ \\
Rectum & $11(18.3 \%)$ \\
Tumour size (cm, mean \pm s.d.) & \\
Differentiation & $4.1 \pm 2.0(0.7-8.7)$ \\
Well & \\
Mod & $26(43.3 \%)$ \\
Por & $30(50.0 \%)$ \\
UICC stage & $4(6.7 \%)$ \\
I & \\
II & $10(16.7 \%)$ \\
III & $23(38.3 \%)$ \\
IV & $12(20.0 \%)$ \\
Lymphatic invasion & $15(25.0 \%)$ \\
$\quad$ None & \\
Present & \\
Venous invasion & $15(25.0 \%)$ \\
None & $45(75.0 \%)$ \\
Present & \\
Lymph node metastasis & \\
None & $28(46.7 \%)$ \\
Present & $32(53.3 \%)$ \\
\hline
\end{tabular}

The resected specimens were fixed in $10 \%$ formalin and embedded in paraffin. Multiple haematoxylin-and-eosin-stained sections of CRC and its related LNs were examined. The following factors were determined for all patients and lesions: age, gender, tumour location, tumour size, tumour differentiation, tumour invasion, LN metastases, and tumour stage. Tumour differentiation and stage were determined according to the WHO and UICC criteria, respectively. All these clinicopathological features are summarised in Table 1.

\section{Immunostaining}

Immunohistochemical staining for SDF-1 $\alpha$ and CXCR4 was performed as described previously (Fukui et al, 2004). In brief, the sections $(4 \mu \mathrm{m}$ thick) were deparaffinised, rehydrated, placed in $0.01 \mathrm{moll}^{-1}$ citrate buffer ( $\mathrm{pH} 6.0$ ), and treated by microwave heating for $10 \mathrm{~min}$. The sections were then preincubated with $0.3 \% \mathrm{H}_{2} \mathrm{O}_{2}$ in methanol for $20 \mathrm{~min}$ at room temperature to quench endogenous peroxidase activity. Subsequently, the sections were immunostained with an UltraTech Kit (Immunotech, Marseille, France) in accordance with the manufacturer's instructions. The sections were pretreated with $1 \%$ bovine serum albumin in phosphate-buffered saline (PBS) and then incubated with anti-SDF- $1 \alpha$ antibody (R\&D Systems Inc., Minneapolis, MN, USA; dilution 1:50) and anti-CXCR4 antibody (BD Biosciences Pharmingen, San Diego, CA, USA; dilution $1: 20$ ) for $1 \mathrm{~h}$ at room temperature. Thereafter, the sections were incubated with biotinylated secondary antibody for $15 \mathrm{~min}$, washed with PBS, and treated with peroxidase-conjugated streptavidin for $20 \mathrm{~min}$. Finally, the sections were incubated in 3,3'-diaminobenzidine tetrahydrochloride with $0.05 \% \mathrm{H}_{2} \mathrm{O}_{2}$ for $3 \mathrm{~min}$ and then counterstained with Carazzi's haematoxylin. Sections of oesophageal cancer that had been confirmed to overexpress these proteins were used as positive controls, and antibodies were not applied to negative controls.
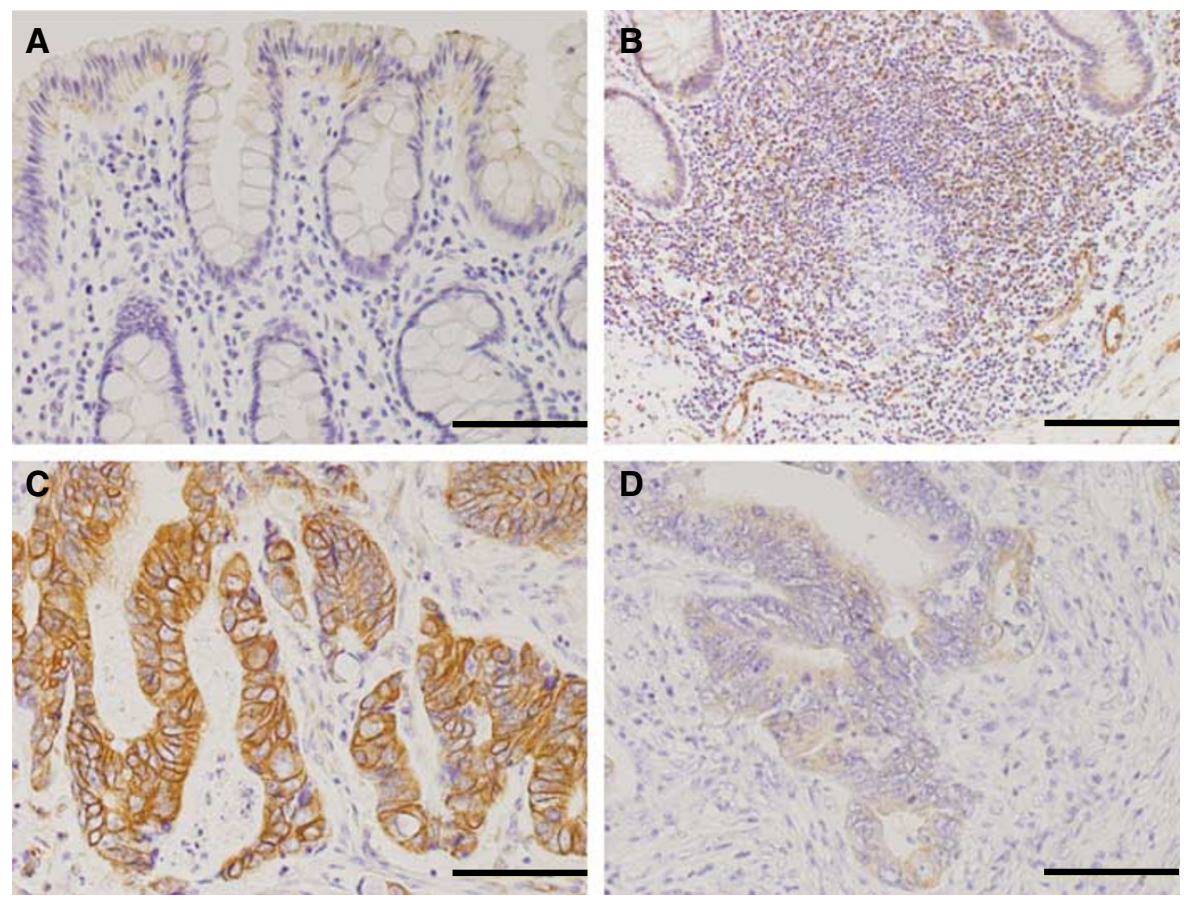

Figure I Immunohistochemistry for SDF-I $\alpha$ in the normal colon and in CRC tissues. (A) Weak to negative immunoreactivity is observed in the cytoplasm of non-neoplastic epithelial cells. (B) Immunoreactivity for SDF-I $\alpha$ is also observed in the lymphoid follicle in the colonic mucosa. (C) Strong type: immunoreactivity is strongly detected in the cytoplasm of cancer cells. (D) Weak type: immunoreactivity is weakly detected in the cytoplasm of cancer cells. Immunoreactivity is also observed in the endothelial cells of the tumour stroma. Scale bars $=100 \mu \mathrm{m}$. 


\section{Evaluation of SDF-1 $\alpha$ and CXCR4 expression}

To examine the pathophysiological role of SDF- $1 \alpha$ and CXCR 4 in metastasis, we assessed the immunoreactivity of SDF- $1 \alpha$ and CXCR4 in the invasive front of CRCs and in their related LN metastases (magnification $\times 200$ ), because the invasive front is a source of metastasised tumour cells and LNs are the first regions that metastasised tumour cells colonise.

In the present study, we defined the normal endothelial cells as an internal control for SDF- $1 \alpha$ immunoreactivity. SDF- $1 \alpha$ immunoreactivity was detected in the cytoplasm of CRC cells. The CRC cells were considered to have strong SDF- $1 \alpha$ expression if their signal was stronger than or equal to that of endothelial cells in the adjacent normal colonic tissues; otherwise, the CRC cells were considered to have weak SDF- $1 \alpha$ expression. The CRC samples were classified into a strong group when CRC cells with strong SDF- $1 \alpha$ expression were dominant at the invasive front of the tumour. Otherwise, we classified them into a weak group.

CXCR4 immunoreactivity was detected in the cytoplasm and in the nucleus of CRC cells. Some CRCs showed clear CXCR4 immunoreactivity in the nucleus and a weak signal in the cytoplasm (nuclear type), whereas others showed no nuclear immunoreactivity but a diffuse signal in the cytoplasm and at the plasma membrane (cytomembrane type). Every lesion was classified as either nuclear or cytomembrane type in accordance with its dominant immunostaining pattern in its invasive front. On the other hand, the CRC samples showing no CXCR4 immunoreactivity were defined as negative.

\section{Nuclear protein extraction and western blot analysis}

A human colorectal cancer cell line, HT29, was maintained in RPMI 1640 medium (Invitrogen, Grand Island, NY, USA) with 10\% fetal bovine serum (Sigma Chemical Co., St Louis, MO, USA). Proteins were extracted from these cells and separated into the nuclear fraction and membrane-cytoplasmic fractions, as described previously (Hoshino et al, 2007). In brief, the cells were mixed with lysis buffer containing $10 \mathrm{~mm}$ Tris- $\mathrm{HCl}(\mathrm{pH} 7.9), 10 \mathrm{~mm}$ $\mathrm{KCl}, 1.5 \mathrm{mM} \mathrm{MgCl}_{2}, 1 \mathrm{mM}$ DTT, $1 \%$ Nonidet $\mathrm{P}-40$, and $1 \times$ proteinase inhibitor (Complete Mini; Roche, Mannheim, Germany). Proteins from the membrane and cytoplasm were extracted from the supernatants, and the precipitate was additionally treated with nuclear lysis buffer containing $20 \mathrm{~mm}$ Tris- $\mathrm{HCl}$ (pH 7.9), $400 \mathrm{~mm} \mathrm{NaCl}, 1.5 \mathrm{~mm} \mathrm{MgCl}_{2}, 0.2 \mathrm{~mm}$ EDTA, $1 \mathrm{~mm}$ DTT, $5 \%$ glycerol, and $1 \times$ proteinase inhibitor (Complete Mini; Roche). After centrifugation, the nuclear protein was extracted from the treated supernatants.

Western blot analysis was carried out as described previously (Sekikawa et al, 2005). Briefly, protein extract $(12.5 \mu \mathrm{g}$ ) was fractionated by sodium dodecyl sulphate-polyacrylamide gel electrophoresis and transferred to a polyvinylidene difluoride membrane. The membrane was incubated with primary antibodies and then with a peroxidase-conjugated secondary antibody. Proteins were detected by an enhanced chemiluminescence system (Amersham Pharmacia Biotech, Buckinghamshire, UK).

\section{Statistical analysis}

The $\chi^{2}$ test was performed to determine correlations among the various parameters, and Fisher's exact test was also used, as necessary. Cumulative survival rate was assessed by the KaplanMeier method and analysed by log-rank test. Multivariate analysis was performed with the Cox proportional hazards model with hazard ratios (HRs) and $95 \%$ confidence intervals (CIs) to evaluate independent prognostic factors. Differences at $P<0.05$ were considered statistically significant.

\section{RESULTS}

\section{Expression of SDF-1 $\alpha$ in normal colon and CRC tissues}

In normal colorectal epithelium adjacent to the tumour, weak to negative immunoreactivity of SDF- $1 \alpha$ was observed in the cytoplasm of non-neoplastic cells (Figure 1A). Stromal cell-derived factor- $1 \alpha$ immunoreactivity was also observed in the lymphoid follicles in the colonic mucosa (Figure 1B).

In the CRC tissues, SDF- $1 \alpha$ immunoreactivity was detected in the cytoplasm of cancer cells and vascular endothelial cells in the tumour stroma (Figure 1C and D). Thirty-eight (63.3\%) of the 60 CRCs showed strong immunoreactivity for SDF- $1 \alpha$ at the invasive front and were classified as strong type. Seventeen CRCs showed weak to faint SDF- $1 \alpha$ immunoreactivity. Five showed no signal and were subsequently also classified as weak type.

\section{Relationship between SDF- $1 \alpha$ expression and clinicopathological features in CRCs}

Tumour stage and prevalence of lymphatic invasion, venous invasion, and LN metastasis were significantly higher in CRCs showing strong SDF-1 $\alpha$ expression than in those with weak expression (Table 2). However, none of the other parameters - age, gender, tumour location, tumour size, or differentiation - had a significant relationship to SDF- $1 \alpha$ expression.

Table 2 Relationship between SDF- $\mid \alpha$ expression and clinicopathological features

\begin{tabular}{|c|c|c|c|}
\hline & \multicolumn{2}{|c|}{ SDF-I $\alpha$ expression } & \multirow[b]{2}{*}{$P$-value } \\
\hline & $\begin{array}{c}\text { Weak } \\
(n=22)\end{array}$ & $\begin{array}{c}\text { Strong } \\
(n=38)\end{array}$ & \\
\hline \multicolumn{4}{|l|}{ Gender } \\
\hline Man & 12 & 29 & 0.145 \\
\hline Woman & 10 & 9 & \\
\hline Age (years, mean \pm s.d.) & $63.7 \pm 10.7$ & $63.9 \pm 11.2$ & 0.962 \\
\hline \multicolumn{4}{|l|}{ Tumour location } \\
\hline Colon & 18 & 31 & 0.999 \\
\hline Rectum & 4 & 7 & \\
\hline Tumour size ( $\mathrm{cm}$, mean \pm s.d.) & $3.6 \pm 2.4$ & $4.4 \pm 1.8$ & 0.128 \\
\hline \multicolumn{4}{|l|}{ Differentiation } \\
\hline Well & 12 & 14 & \\
\hline Mod & 9 & 21 & 0.185 \\
\hline Por & 1 & 3 & \\
\hline \multicolumn{4}{|l|}{ UICC stage } \\
\hline 1 & 8 & 2 & \\
\hline$\|$ & 10 & 13 & 0.0002 \\
\hline III & 3 & 9 & \\
\hline IV & । & 14 & \\
\hline \multicolumn{4}{|l|}{ Lymphatic invasion } \\
\hline None & 11 & 4 & 0.001 \\
\hline Present & 11 & 34 & \\
\hline \multicolumn{4}{|l|}{ Venous invasion } \\
\hline None & 15 & 13 & 0.016 \\
\hline Present & 7 & 25 & \\
\hline \multicolumn{4}{|l|}{ Lymph node metastasis } \\
\hline None & 18 & 15 & 0.003 \\
\hline Present & 4 & 23 & \\
\hline
\end{tabular}




\section{Expression of CXCR4 in normal colon and CRC tissues}

In the normal colorectal epithelium adjacent to the tumour, weak immunoreactivity for CXCR4 was generally detected in the cytoplasm and plasma membrane of non-neoplastic epithelial cells (Figure 2A).

In the CRC tissues, CXCR4 immunoreactivity was found not only in cancer cells but also in lymphocytes in the tumour stroma. Here, we focussed on the immunostaining pattern for CXCR4 in cancer cells at the invasive fronts of tumours. Forty-seven $(78.3 \%)$ of the 60 CRCs were positive for CXCR4 expression at the invasive front. In $29(61.7 \%)$ of these 47 CXCR4-positive CRCs, CXCR4 immunoreactivity was clearly localised in the nucleus (nuclear type; Figure $2 \mathrm{~B}$ ). In the remaining 18 cases (38.3\%), it was detected diffusely in the cytoplasm and plasma membrane (cytomembrane type; Figure 2C).

\section{Localisation of CXCR4 proteins in the CRC cell line}

We examined the specificity of CXCR4 immunoreactivity by using the CRC cell line HT29. CXCR4 immunoreactivity was detected not only weakly at the plasma membrane but also strongly on the nucleus strongly (Figure $3 \mathrm{~A}$ ).

Localisation of CXCR4 proteins was also examined in HT29 cells by western blot analysis. Western blots revealed CXCR4 protein in not only the cytomembrane fraction but also the nucleus (Figure 3B).

\section{Relationship between CXCR4 expression and clinicopathological features in CRCs}

CXCR4 expression was significantly positive in CRCs with high tumour stage and with LN metastasis (Table 3). Additionally,
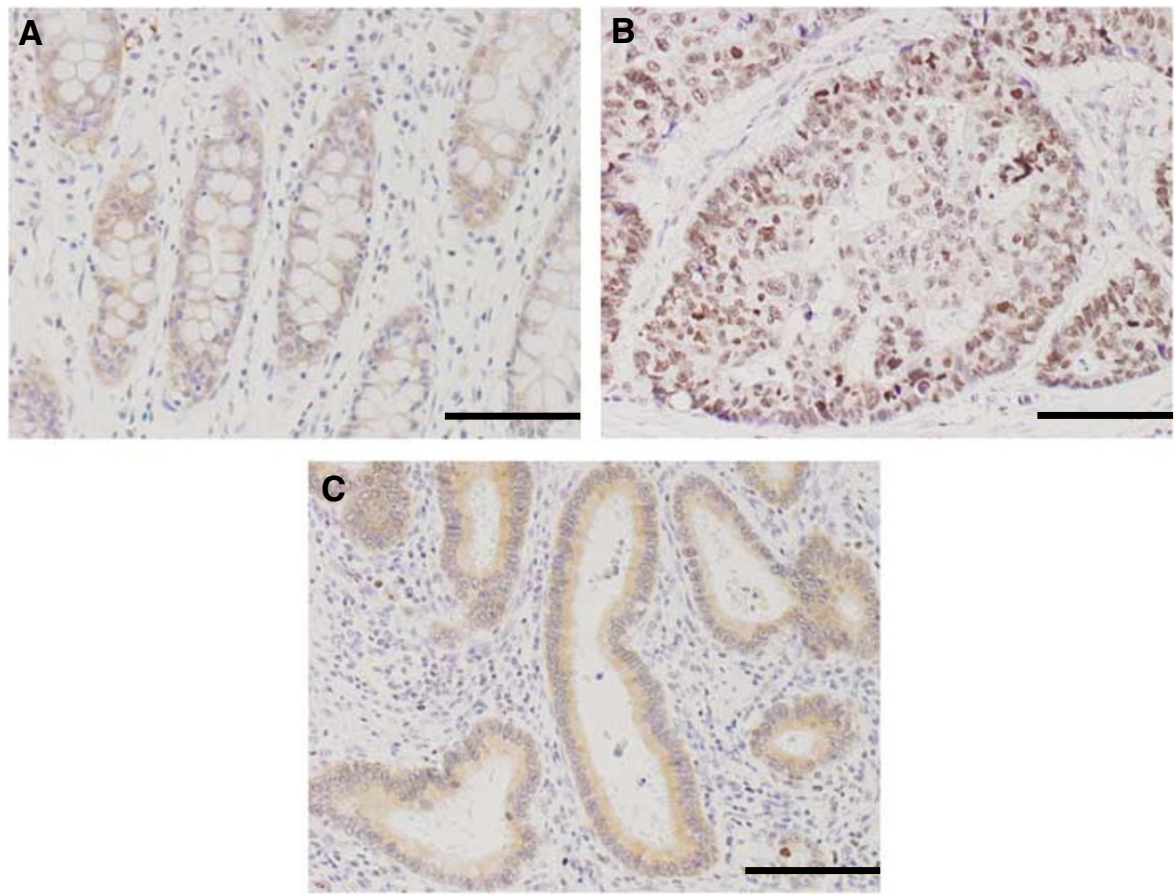

Figure 2 Immunohistochemistry for CXCR4 in the normal colon and in CRC tissues. (A) Weak immunoreactivity is observed in the cytoplasm and plasma membrane of non-neoplastic epithelium cells. (B) Nuclear type: immunoreactivity is detected in the cytoplasm of cancer cells weakly and in the nuclei strongly. (C) Cytomembrane type: immunoreactivity is detected in the cytoplasm and plasma membrane of cancer cells. Scale bars $=100 \mu$ m.

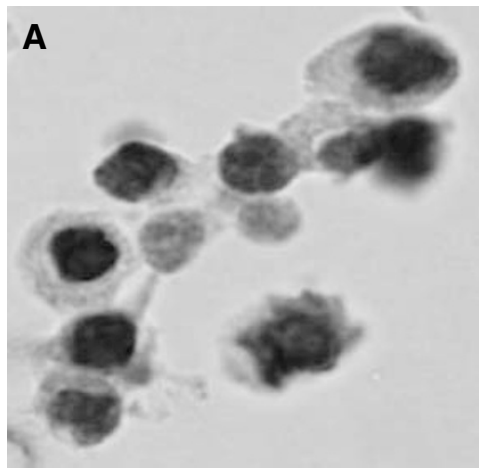

B

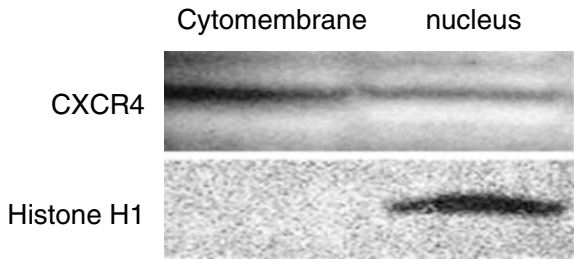

Figure 3 Subcellular localisation of CXCR4 in the CRC cell line HT29. (A) Immunohistochemistry. CXCR4 immunoreactivity is detected not only weakly at the plasma membrane but also strongly in the nuclei. (B) Western blot analysis. CXCR4 immunoreactivity is detected not only in the cytoplasmic and membranous ('cytomembrane') fraction but also in the nuclear ('nuclear') protein fraction from HT29 cells. 
Table 3 Comparison of the clinicopathologial features between the CXCR4-positive and CXCR4-negative CRC patients

\begin{tabular}{|c|c|c|c|}
\hline & $\begin{array}{l}\text { Positive } \\
(n=47)\end{array}$ & $\begin{array}{c}\text { Negative } \\
(n=13)\end{array}$ & $P$-value \\
\hline \multicolumn{4}{|l|}{ Gender } \\
\hline Man & 31 & 10 & 0.522 \\
\hline Woman & 16 & 3 & \\
\hline Age (years, mean \pm s.d.) & $64.0 \pm 10.8$ & $63.2 \pm 11.9$ & 0.829 \\
\hline \multicolumn{4}{|l|}{ Tumour location } \\
\hline Colon & 38 & | | & 0.999 \\
\hline Rectum & 9 & 2 & \\
\hline Tumour size (cm, mean \pm s.d.) & $4.3 \pm 1.8$ & $3.4 \pm 2.8$ & 0.158 \\
\hline \multicolumn{4}{|l|}{ Differentiation } \\
\hline Well & 20 & 6 & \\
\hline Mod & 24 & 6 & 0.872 \\
\hline Por & 3 & 1 & \\
\hline \multicolumn{4}{|l|}{ UICC stage } \\
\hline I & 3 & 7 & \\
\hline$\|$ & 18 & 4 & $<0.0001$ \\
\hline |l| & $\mid 1$ & 2 & \\
\hline IV & 15 & 0 & \\
\hline \multicolumn{4}{|l|}{ Lymphatic invasion } \\
\hline None & 9 & 6 & 0.070 \\
\hline Present & 38 & 7 & \\
\hline \multicolumn{4}{|l|}{ Venous invasion } \\
\hline None & 19 & 9 & 0.115 \\
\hline Present & 28 & 4 & \\
\hline \multicolumn{4}{|l|}{ Lymph node metastasis } \\
\hline None & 21 & 12 & 0.004 \\
\hline Present & 26 & 1 & \\
\hline
\end{tabular}

CXCR4 expression positivity tended to be higher in CRCs with lymphatic invasion than in those without.

We next divided CXCR4-positive CRCs into nuclear and cytomembrane types and further investigated the importance of CXCR4 immunostaining patterns (Table 4). Comparison of nuclear- and cytomembrane-type CXCR4-positive CRCs revealed that the nuclear-type CRCs were significantly more likely to show poor differentiation, high tumour stage, and frequent $\mathrm{LN}$ metastasis. In addition, lymphatic invasion tended to be more frequent in nuclear-type CRCs. Moreover, comparison of CXCR4negative and CXCR4 nuclear-type-positive CRCs revealed that malignant potential, as indicated by tumour stage, lymphatic invasion, venous invasion, and LN metastasis, was clearly higher in CXCR4 nuclear-type-positive tumours.

\section{Relationship between SDF-1 $\alpha$ and CXCR4 expression in primary CRCs}

CXCR4-positive CRCs showed significantly stronger SDF- $1 \alpha$ expression than did negative ones (Table 5; $P=0.002$ ). However, among the CXCR4-positive CRCs, SDF- $1 \alpha$ expression did not differ between the nuclear and cytomembrane types.

\section{Expression of SDF-1 $\alpha$ and CXCR4 in metastasised tumour cells in LNs}

Twenty-seven CRCs showed metastasis to their related LN. Among these primary CRCs, 23 (85.2\%) had strong expression of SDF- $1 \alpha$.
Table 4 Relationship between CXCR4 immunostaining pattern and clinicopathological features in patients with CXCR4-positive CRC

\begin{tabular}{|c|c|c|c|}
\hline & $\begin{array}{l}\text { Nuclear } \\
(n=29)\end{array}$ & $\begin{array}{c}\text { Cytomembrane } \\
(n=18)\end{array}$ & $P$-value \\
\hline \multicolumn{4}{|l|}{ Gender } \\
\hline Man & 19 & 12 & 0.999 \\
\hline Woman & 10 & 6 & \\
\hline Age (years, mean \pm s.d.) & $63.0 \pm 11.4$ & $65.6 \pm 9.9$ & 0.419 \\
\hline \multicolumn{4}{|l|}{ Tumour location } \\
\hline Colon & 21 & 17 & 0.999 \\
\hline Rectum & 8 & I & \\
\hline $\begin{array}{l}\text { Tumour size }(\mathrm{cm} \text {, } \\
\text { mean } \pm \text { s.d.) }\end{array}$ & $4.3 \pm 1.7$ & $4.2 \pm 2.0$ & 0.882 \\
\hline \multicolumn{4}{|l|}{ Differentiation } \\
\hline Well & 9 & 11 & \\
\hline Mod & 17 & 7 & 0.028 \\
\hline Por & 3 & 0 & \\
\hline \multicolumn{4}{|l|}{ UICC stage } \\
\hline 1 & 0 & 3 & \\
\hline$\|$ & 9 & 9 & 0.022 \\
\hline III & 9 & 2 & \\
\hline IV & 11 & 4 & \\
\hline \multicolumn{4}{|l|}{ Lymphatic invasion } \\
\hline None & 3 & 6 & 0.068 \\
\hline Present & 26 & 12 & \\
\hline \multicolumn{4}{|l|}{ Venous invasion } \\
\hline None & 9 & 10 & 0.172 \\
\hline Present & 20 & 8 & \\
\hline \multicolumn{4}{|l|}{ Lymph node metastasis } \\
\hline None & 9 & 12 & 0.036 \\
\hline Present & 20 & 6 & \\
\hline
\end{tabular}

Table 5 Relationship between CXCR4 expression and SDF- I $\alpha$ expression in primary tumour

\begin{tabular}{|c|c|c|c|c|}
\hline & \multicolumn{3}{|c|}{ CXCR4 positive } & \multirow[b]{2}{*}{ CXCR4 negative } \\
\hline & Nuclear & Cytomembrane & Total & \\
\hline \multicolumn{5}{|c|}{ SDF- $\mid \alpha$ expression } \\
\hline Weak & 7 & 5 & 12 & 10 \\
\hline Strong & 22 & 13 & $35^{a}$ & 3 \\
\hline
\end{tabular}

Twenty-four (88.9\%) of the 27 metastasised tumours in LNs (MTLNs) showed strong expression of SDF-1 $\alpha$. Thus, most of the CRCs with LN metastases $(n=22,81.5 \%)$ showed strong SDF- $1 \alpha$ expression, not only in the primary lesion but also in their MTLNs (Figure 4A).

Twenty-six (96.3\%) of the 27 primary CRCs with LN metastases were positive for CXCR4 expression: 20 (74.1\%) with nuclear patterns and $6(22.2 \%)$ with cytomembrane patterns (Figure 5). Twenty-three $(85.2 \%)$ of the 27 MTLNs were positive for CXCR4 expression. Sixteen (69.6\%) of the MTLNs had CXCR4 immunostaining patterns of the cytomembrane type and seven $(30.4 \%)$ were of the nuclear type. Interestingly, 11 (55.0\%) of the 20 primary CRCs that had nuclear-type CXCR4 immunoreactivity had cytomembrane-type CXCR4 positivity in their LNs. However, five 

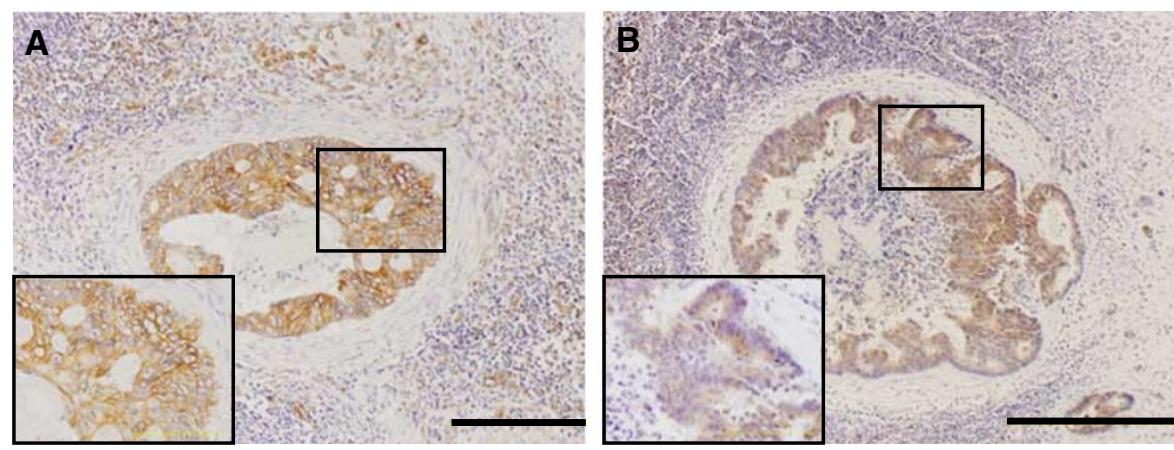

Figure 4 Expression of SDF- $\mid \alpha$ and CXCR4 in MTLNs. Representative photomicrographs of MTLNs, showing (A) strong SDF- $\mid \alpha$ expression and (B cytomembrane-type CXCR4. Scale bars $=100 \mu \mathrm{m}$.

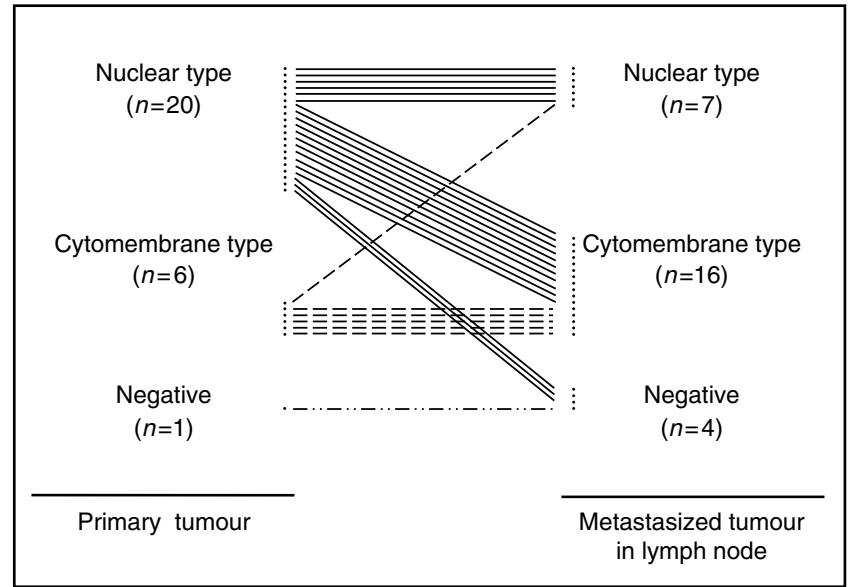

Figure 5 Immunostaining pattern of CXCR4 in primary CRCs and MTLNs. MTLNs show significant cytomembranous immunoreactivity even when the primary tumours show nuclear immunoreactivity $(n=27$, $P=0.012$.

(83.3\%) of the six CRCs that had cytomembrane-type CXCR4 immunoreactivity had the same CXCR4 immunoreactivity patterns in their MTLNs. These findings suggest that MTLNs are significantly more likely to show cytomembrane pattern CXCR4 immunoreactivity even when their primary CRCs show nucleartype CXCR4 immunoreactivity (Figure 4B).

\section{Survival analysis}

Log-rank statistics showed that lymphatic invasion, LN metastasis, and disease stage were significant prognostic indicators for overall patient survival $(P=0.043,0.0005$, and $<0.0005$, respectively). There was no significant correlation between prognosis and other clinicopathological features.

To assess the prognostic significance of SDF- $1 \alpha$ and CXCR 4 expression, Kaplan-Meier survival curves were constructed. The prognosis of CRC patients with strong SDF- $1 \alpha$ expression was significantly worse than that of CRC patients with weak SDF- $1 \alpha$ expression (Figure 6A). Patients with CXCR4-positive CRCs also had significantly worse outcomes than those with CXCR4-negative ones (Figure 6B). Furthermore, CRC patients with nuclear-type CXCR4 expression tended to have worse outcomes than those with cytomembrane-type expression (Figure 6C).

Multivariate analysis by Cox regression and correction for disease stage, CXCR4 expression, and SDF- $1 \alpha$ expression showed
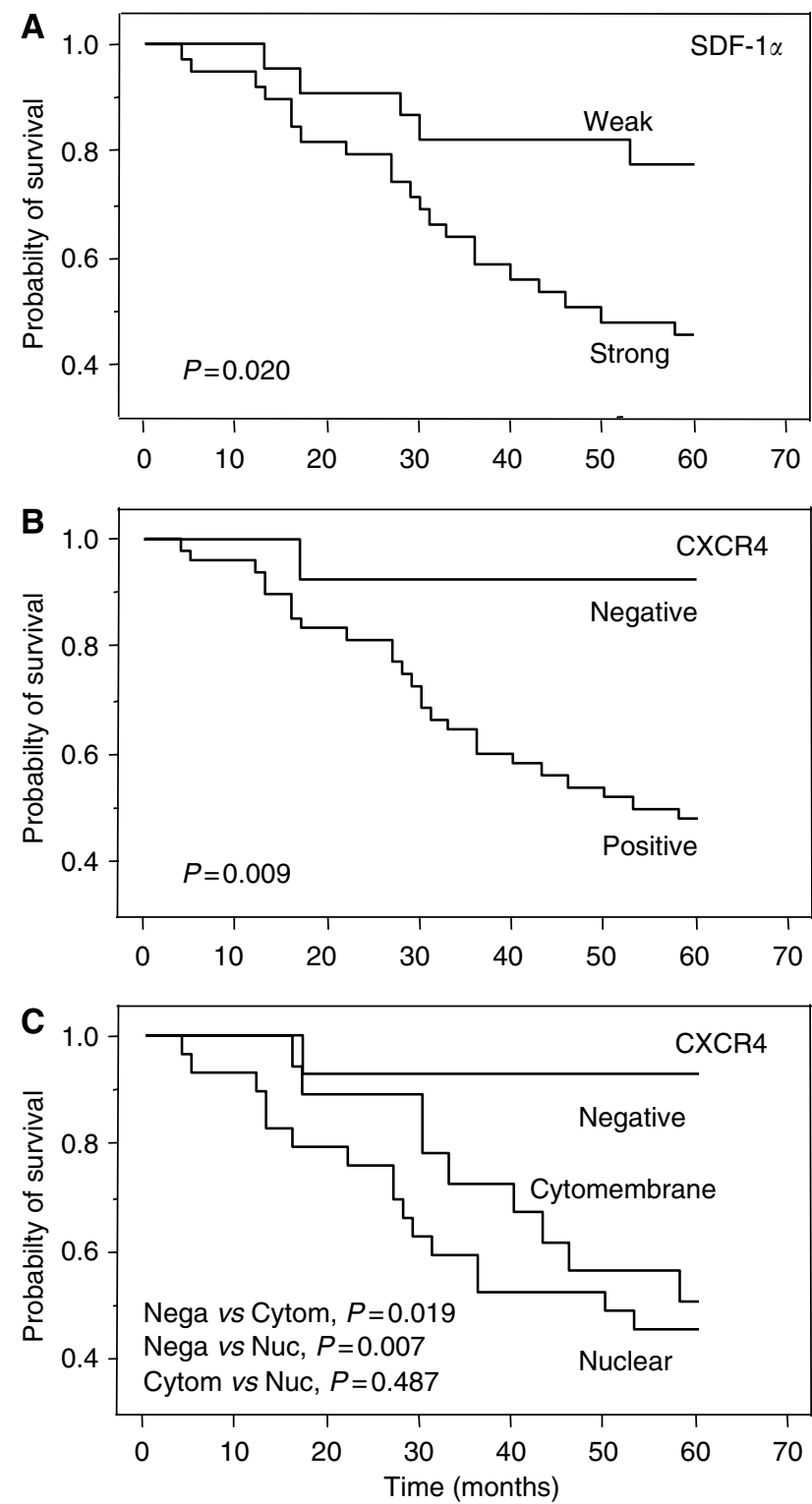

Figure 6 Overall survival according to (A) SDF- $\mid \alpha$ immunoreactivity; (B) CXCR4 immunoreactivity; and (C) CXCR4 immunostaining pattern in patients with CRCs $(n=60)$. Kaplan-Meier survival curves were constructed and pairwise differences were analysed by log-rank test. Nega, negative; Cytom, cytomembrane; Nuc, nuclear. 
that stage was an independent prognostic factor $(\mathrm{HR}=2.63,95 \%$ CI $1.08-6.41, P=0.033)$, whereas SDF- $1 \alpha \quad(\mathrm{HR}=1.46,95 \% \mathrm{CI}$ $0.52-4.10, P=0.475)$ and CXCR4 expression ( $\mathrm{HR}=5.08,95 \%$ CI $0.65-40.0, P=0.123$ ) were not statistically significant.

\section{DISCUSSION}

CXCR4 has been shown experimentally to be crucial for cancer cell adhesion and/or migration (Kawamata et al, 2003), suggesting the involvement of CXCR4 in tumour invasion and metastasis. Supporting such in vitro data, our clinicopathological study revealed that CXCR4 expression was significantly positive in CRCs with a high tumour stage and LN metastasis, and patients with CXCR4-positive CRCs showed a significantly worse outcome than those in whom CRCs were negative, suggesting that CXCR4 is a significant prognostic marker in CRC patients.

Interestingly, we found that CRC cells had two distinct immunostaining patterns for CXCR4: cytomembrane and nuclear types, similar to those reported in cases of hepatocellular carcinoma (Shibuta et al, 2002), breast cancer (Kato et al, 2003; Shim et al, 2006), lung cancer (Spano et al, 2004), and nasopharyngeal carcinoma (Wang et al, 2005). As CXCR4 is a transmembrane protein, it was originally believed that its expression would be detectable at the plasma membrane and in the cytoplasm, and in contrast, that nuclear CXCR4 expression would be detected nonspecifically by immunohistochemistry. However, our initial examination of the localisation of CXCR4 in CRC cell lines showed that CXCR4 immunoreactivity was detectable not only in the cytomembrane but also in nuclear protein fractions, suggesting the specificity of CXCR4 immunoreactivity in the nuclei of CRC cells. Of note, CRC patients with nuclear-type CXCR4 expression showed more frequent LN metastasis, poor differentiation, and worse outcome than those with cytomembrane-type expression, suggesting that nuclear expression of CXCR4 may play a role in the progression of CRC.

Although a few in vitro studies have described SDF- $1 \alpha$ expression in CRC cell lines (Brand et al, 2005; Wendt et al, 2006), ours is the first demonstration that considerable numbers of human CRC lesions indeed produce SDF- $1 \alpha$. Moreover, it was important that SDF- $1 \alpha$ expression was associated with not only lymphatic invasion, venous invasion, and LN metastasis but also survival of CRC patients. In conflict with our present data, a single study by northern blot preliminarily reported that $S D F-1 \alpha$ mRNA expression was decreased in CRC tissues in comparison with normal colon tissues (Shibuta et al, 1997). However, we found that SDF- $1 \alpha$ was moderately produced in the lymphoid follicles but faintly by colorectal epithelial cells in normal colon tissues. Thus, northern blot analysis of CRC tissues might not compare the SDF$1 \alpha$ mRNA levels of normal colorectal epithelial cells and CRC cells. Although CRC tissues also contain SDF- $1 \alpha$-positive stromal cells, immunohistochemistry clearly demonstrated that the cancerous cells in more than $50 \%$ of CRC samples examined had much stronger expression of SDF- $1 \alpha$ than their neighbouring normal colonic epithelial cells. Accordingly, as with CXCR4 overexpres- sion, the SDF- $1 \alpha-$ CXCR 4 axis appears to play important roles in the progression of CRC.

One concern is the molecular mechanism of nuclear CXCR4 expression and the pathobiological roles of the SDF- $1 \alpha-$ CXCR 4 axis in CRC progression. Stromal cell-derived factor- $1 \alpha$ stimulation triggers CXCR4 internalisation, involving G-protein-coupled receptor kinases, followed by the binding of $\beta$-arrestin and subsequently CXCR4 endocytosis (Haribabu et al, 1997; Orsini et al, 1999; Cheng et al, 2000; Burger et al, 2003). On the other hand, Zeelenberg et al (2003) showed that endogenous SDF-1 $\alpha$ binds newly synthesised CXCR 4 and subsequently inhibits the translocation of CXCR4 to the cell surface. In these contexts, we expected that SDF- $1 \alpha$ expression might be associated with nuclear CXCR4 expression in CRC cells, and therefore investigated the CXCR4 expression pattern in CRC cells that had metastasised to LNs, as SDF- $1 \alpha$ is abundantly produced and furthermore, most MTLNs showed strong SDF- $1 \alpha$ expression there. However, contrary to expectation, even CRC patients with nuclear patterns of CXCR4 expression in the primary lesion frequently had cytomembrane-type CXCR4-positive tumours in the LNs. Moreover, we observed no significant relationships between SDF- $1 \alpha$ expressional intensity and CXCR4 expression pattern in the primary CRCs. Thus, considering these findings as a whole, it is difficult to explain the molecular mechanism of nuclear CXCR4 expression in CRC cells in terms of its association with SDF- $1 \alpha$ alone. On the other hand, it is known that hypoxia-inducible factor- $1 \alpha$ (HIF- $1 \alpha)$ plays a critical role in CXCR4 expression in the tumour cells under hypoxic condition (Pouysségur et al, 2006). Interestingly, Shim et al (2006) have recently reported that HIF-1 $\alpha$ expression is reduced in MTLNs of patients with breast cancer and moreover that MTLNs showed cytoplasmic immunoreactivity for CXCR4 expression. Although it is still unclear why immunostaining pattern of CXCR4 in MTLNs is different from that in primary lesions, SDF- $1 \alpha$ and HIF- $1 \alpha$ may be possible keys to determine CXCR4 expression pattern.

In summary, we demonstrated here that both CXCR4 and SDF$1 \alpha$ expressions are closely associated with LN metastasis and poor prognosis in patients with CRC. Moreover, we clarified the fact that CXCR4 is detectable not only at the plasma membrane but also in the cytoplasm or nucleus of CRC cells, although the molecular mechanism of nuclear CXCR4 expression remains to be elucidated. As nuclear CXCR4 expression in the primary CRC may reflect increased potential for LN metastasis, the pathobiological significance of translocated CXCR4 needs to be investigated in future studies.

\section{ACKNOWLEDGEMENTS}

We thank Chiaki Matsuyama, Ayako Shimizu, Takako Ono, Midori Katayama, Atsuko Kikuchi, and Sachiko Miyahara (Department of Surgical and Molecular Pathology, Dokkyo University School of Medicine, Tochigi, Japan) for their excellent technical and secretarial assistance.

\section{REFERENCES}

Baggiolini M, Dewald B, Moser B (1997) Human chemokines: an update. Annu Rev Immunol 15: 675-705

Brand S, Dambacher J, Beigel F, Olszak T, Diebold J, Otte JM, Goke B, Eichhorst ST (2005) CXCR4 and CXCL12 are inversely expressed in colorectal cancer cells and modulate cancer cell migration, invasion and MMP-9 activation. Exp Cell Res 310: 117-130

Burger M, Glodek A, Hartmann T, Schmitt-Graff A, Silberstein LE, Fujii N, Kipps TJ, Burger JA (2003) Functional expression of CXCR4 (CD184) on small-cell lung cancer cells mediates migration, integrin activation, and adhesion to stromal cells. Oncogene 22: $8093-8101$

Cheng ZJ, Zhao J, Sun Y, Hu W, Wu YL, Cen B, Wu GX, Pei G (2000) betaarrestin differentially regulates the chemokine receptor CXCR4-mediated signaling and receptor internalization, and this implicates multiple interaction sites between beta-arrestin and CXCR4. J Biol Chem 275: 2479-2485

Fernandis AZ, Prasad A, Band H, Klosel R, Ganju RK (2004) Regulation of CXCR4-mediated chemotaxis and chemoinvasion of breast cancer cells. Oncogene 23: $157-167$ 
Fukui H, Fujii S, Takeda J, Kayahara T, Sekikawa A, Nanakin A, Suzuki K, Hisatsune H, Seno H, Sawada M, Fujimori T, Chiba T (2004) Expression of reg I alpha protein in human gastric cancers. Digestion 69: $177-184$

Haribabu B, Richardson RM, Fisher I, Sozzani S, Peiper SC, Horuk R, Ali H, Snyderman R (1997) Regulation of human chemokine receptors CXCR4. Role of phosphorylation in desensitization and internalization. J Biol Chem 272: 28726-28731

Hartmann TN, Burger JA, Glodek A, Fujii N, Burger M (2005) CXCR4 chemokine receptor and integrin signaling co-operate in mediating adhesion and chemoresistance in small cell lung cancer (SCLC) cells. Oncogene 24: $4462-4471$

Hoshino M, Fukui H, Ono Y, Sekikawa A, Ichikawa K, Tomita S, Imai Y, Imura J, Hiraishi H, Fujimori $\mathrm{T}$ (2007) Nuclear expression of phosphorylated EGFR is associated with poor prognosis of patients with esophageal squamous cell carcinoma. Pathobiology 74: 15-21

Kato M, Kitayama J, Kazama S, Nagawa H (2003) Expression pattern of CXC chemokine receptor- 4 is correlated with lymph node metastasis in human invasive ductal carcinoma. Breast Cancer Res 5: 144-150

Kawamata H, Furihata T, Omotehara F, Sakai T, Horiuchi H, Shinagawa Y, Imura J, Ohkura Y, Tachibana M, Kubota K, Terano A, Fujimori T (2003) Identification of genes differentially expressed in a newly isolated human metastasizing esophageal cancer cell line, T.Tn-AT1, by cDNA microarray. Cancer Sci 94: 699-706

Kayali AG, Van Gunst K, Campbell IL, Stotland A, Kritzik M, Liu G, Flodström-Tullberg M, Zhang YQ, Sarvetnick N (2003) The stromal cell-derived factor-1alpha/CXCR4 ligand-receptor axis is critical for progenitor survival and migration in the pancreas. J Cell Biol 163: $859-869$

Murdoch C (2000) CXCR4: chemokine receptor extraordinaire. Immunol Rev 177: $175-184$

Orsini MJ, Parent JL, Mundell SJ, Benovic JL, Marchese A (1999) Trafficking of the HIV coreceptor CXCR4. Role of arrestins and identification of residues in the c-terminal tail that mediate receptor internalization. J Biol Chem 274: 31076-31086

Pouysségur J, Dayan F, Mazure NM (2006) Hypoxia signaling in cancer and approached to enforce tumor regression. Nature 441: 437-443

Rollins BJ (1997) Chemokines. Blood 90: 909-928

Sekikawa A, Fukui H, Fujii S, Takeda J, Nanakin A, Hisatsune H, Seno H, Takasawa S, Okamoto H, Fujimori T, Chiba T (2005) REG Ialpha protein may function as a trophic and/or anti-apoptotic factor in the development of gastric cancer. Gastroenterology 128: 642-653
Shibuta K, Begum NA, Mori M, Shimoda K, Akiyoshi T, Barnard GF (1997) Reduced expression of the CXC chemokine hIRH/SDF-1alpha mRNA in hepatoma and digestive tract cancer. Int J Cancer 73: 656-662

Shibuta K, Mori M, Shimoda K, Inoue H, Mitra P, Barnard GF (2002) Regional expression of CXCL12/CXCR4 in liver and hepatocellular carcinoma and cell-cycle variation during in vitro differentiation. Jpn J Cancer Res 93: 789-797

Shim H, Lau SK, Devi S, Yoon Y, Cho HT, Liang Z (2006) Lower expression of CXCR4 in lymph node metastases than in primary breast cancers: potential regulation by ligand-dependent degradation and HIF-1alpha. Biochem Biophys Res Commun 346: 252-258

Soriano SF, Serrano A, Hernanz-Falcon P, Martin de Ana A, Monterrubio M, Martinez C, Rodriguez-Frade JM, Mellado M (2003) Chemokines integrate JAK/STAT and G-protein pathways during chemotaxis and calcium flux responses. Eur J Immunol 33: 1328-1333

Spano JP, Andre F, Morat L, Sabatier L, Besse B, Combadiere C, Deterre P, Martin A, Azorin J, Valeyre D, Khayat D, Le Chevalier T, Soria JC (2004) Chemokine receptor CXCR4 and early-stage non-small cell lung cancer: pattern of expression and correlation with outcome. Ann Oncol 15: 613-617

Tachibana K, Hirota S, Iizasa H, Yoshida H, Kawabata K, Kataoka Y, Kitamura Y, Matsushima K, Yoshida N, Nishikawa S, Kishimoto T, Nagasawa T (1998) The chemokine receptor CXCR4 is essential for vascularization of the gastrointestinal tract. Nature 393: 591-594

Tashiro K, Tada H, Heilker R, Shirozu M, Nakano T, Honjo T (1993) Signal sequence trap: a cloning strategy for secreted proteins and type I membrane proteins. Science 26: $600-603$

Vlahakis SR, Villasis-Keever A, Gomez T, Vanegas M, Vlahakis N, Paya CV (2002) G protein-coupled chemokine receptors induce both survival and apoptotic signaling pathways. J Immunol 169: 5546-5554

Wang N, Wu QL, Fang Y, Mai HQ, Zeng MS, Shen GP, Hou JH, Zeng YX (2005) Expression of chemokine receptor CXCR4 in nasopharyngeal carcinoma: pattern of expression and correlation with clinical outcome. J Transl Med 3: 26

Wendt MK, Johanesen PA, Kang-Decker N, Binion DG, Shah V, Dwinell MB (2006) Silencing of epithelial CXCL12 expression by DNA hypermethylation promotes colonic carcinoma metastasis. Oncogene 25: 4986-4997

Zeelenberg IS, Ruuls-Van Stalle L, Roos E (2003) The chemokine receptor CXCR4 is required for outgrowth of colon carcinoma micrometastases. Cancer Res 63: 3833-3839

Zou YR, Kottmann AH, Kuroda M, Taniuchi I, Littman DR (1998) Function of the chemokine receptor CXCR4 in haematopoiesis and in cerebellar development. Nature 393: 595-599 